\title{
Functional significance of glutamate-cysteine ligase modifier for erythrocyte survival in vitro and in vivo
}

\author{
M Föller ${ }^{1,5}$, IS Harris ${ }^{1,5}$, A Elia ${ }^{1}, \mathrm{R}$ John $^{2}, \mathrm{~F}$ Lang $^{3}$, TJ Kavanagh ${ }^{4}$ and TW Mak ${ }^{*, 1}$
}

Erythrocytes endure constant exposure to oxidative stress. The major oxidative stress scavenger in erythrocytes is glutathione. The rate-limiting enzyme for glutathione synthesis is glutamate-cysteine ligase, which consists of a catalytic subunit (GCLC) and a modifier subunit (GCLM). Here, we examined erythrocyte survival in GCLM-deficient $\left(\mathrm{gclm}^{-/-}\right)$mice. Erythrocytes from $\mathrm{gclm}^{-1-}$ mice showed greatly reduced intracellular glutathione. Prolonged incubation resulted in complete lysis of $\mathrm{gclm}^{-1-}$ erythrocytes, which could be reversed by exogenous delivery of the antioxidant Trolox. To test the importance of GCLM in vivo, mice were treated with phenylhydrazine (PHZ; $0.07 \mathrm{mg} / \mathrm{g} \mathrm{b.w.)}$ to induce oxidative stress. $\mathrm{Gclm}^{-/-}$mice showed dramatically increased hemolysis compared with $\mathrm{gclm}{ }^{+/+}$controls. In addition, PHZ-treated $\mathrm{gclm}^{-/-}$mice displayed markedly larger accumulations of injured erythrocytes in the spleen than $\mathrm{gclm}^{+I+}$ mice within $24 \mathrm{~h}$ of treatment. Iron staining indicated precipitations of the erythrocyte-derived pigment hemosiderin in kidney tubules of $\mathrm{gclm}^{-/-}$mice and none in $\mathrm{gclm}^{+/+}$ controls. In fact, $24 \mathrm{~h}$ after treatment, kidney function began to diminish in $\mathrm{gclm}^{-1-}$ mice as evident from increased serum creatinine and urea. Consequently, while all PHZ-treated $\mathrm{gclm}^{+/+}$mice survived, $90 \%$ of PHZ-treated $\mathrm{gclm}^{-/-}$mice died within 5 days of treatment. In vitro, upon incubation in the absence or presence of additional oxidative stress, $\mathrm{gclm}^{-1-}$ erythrocytes exposed significantly more phosphatidylserine, a cell death marker, than $\mathrm{gclm}{ }^{+/+}$erythrocytes, an effect at least partially due to increased cytosolic $\mathrm{Ca}^{2+}$ concentration. Under resting conditions, $\mathrm{gclm}^{-1-}$ mice exhibited reticulocytosis, indicating that the enhanced erythrocyte death was offset by accelerated erythrocyte generation. GCLM is thus indispensable for erythrocyte survival, in vitro and in vivo, during oxidative stress.

Cell Death and Differentiation (2013) 20, 1350-1358; doi:10.1038/cdd.2013.70; published online 21 June 2013

As $\mathrm{O}_{2}$-carrying cells, erythrocytes are constantly exposed to oxidative stress and therefore maintain high intracellular concentrations of glutathione, a major scavenger of reactive oxygen species (ROS). ${ }^{1}$ Glutathione is a tripeptide ( $\gamma$-glutamyl-cysteinyl-glycine) that is ubiquitously expressed. ${ }^{2}$ The first and rate-limiting enzyme for glutathione synthesis is glutamate-cysteine ligase, a heterodimer comprising a catalytic (GCLC) and a modifier (GCLM) subunit. ${ }^{3}$ Each subunit is coded by a separate gene, and even in the absence of GCLM, GCLC is still catalytically active. ${ }^{4}$ However, GCLM lowers the $K_{M}$ value for the substrate glutamate and raises the $\mathrm{K}_{\mathrm{i}}$ value for $\mathrm{GSH}$, thereby optimizing the conditions for glutathione synthesis. ${ }^{4}$ Whereas GCLC deficiency is embryonic lethal in mice, $\mathrm{gclm}^{-/-}$mice do not have an obvious phenotype under resting conditions, despite the fact that glutathione levels in many of their tissues are only $\sim 10-20 \%$ of those in wild-type mice..$^{3,5}$ In men, a common GCLM gene polymorphism that is associated with lower
GCLM expression has been shown to increase the risk of myocardial infarction ${ }^{6}$ or may be linked to schizophrenia, ${ }^{7}$ although this association is discussed controversially. ${ }^{8}$ $\mathrm{Gclm}^{-/-}$mice are a valuable model to study conditions of low glutathione similar to those that are the consequence of genetic polymorphisms. ${ }^{4}$

Erythrocytes are devoid of organelles but certain stressors, among them ROS, can trigger their programmed death. ${ }^{9-11}$ ROS activates cation channels in the erythrocyte membrane, thereby allowing $\mathrm{Ca}^{2+}$ to enter the cell. ${ }^{11}$ Although the exact mechanism is not completely understood, it is known that $\mathrm{Ca}^{2+}$ triggers the translocation of membrane phosphatidylserine (PS) (a marker of cell death) from the inner leaflet to the outer leaflet. ${ }^{12}$ PS-externalizing erythrocytes may be sequestered mainly in the spleen before lysis. ${ }^{11,12}$ Severe increases in ROS may induce rapid hemolysis, with the immediate rupture of the erythrocyte membrane and release of hemoglobin $(\mathrm{Hb})$ into the serum. ${ }^{12}$ Large amounts of free serum

\footnotetext{
${ }^{1}$ Department of Medical Biophysics and Immunology, The Campbell Family Institute for Breast Cancer Research at Princess Margaret Hospital, Ontario Cancer Institute, University Health Network, Toronto, Ontario, Canada; ${ }^{2}$ Department of Pathology, University Health Network, Toronto, Ontario, Canada; ${ }^{3}$ Department of Physiology, University of Tübingen, Tübingen, Germany and ${ }^{4}$ Department of Environmental and Occupational Health Sciences, University of Washington, Seattle, WA, USA ${ }^{*}$ Corresponding author: TW Mak, Department of Medical Biophysics and Immunology, The Campbell Family Institute for Breast Cancer Research at Princess Margaret Hospital, Ontario Cancer Institute, University Health Network, 620 University Avenue, Suite 706, Toronto, Ontario M5G 2C1, Canada. Tel: +1 416 946 2234; Fax: +1 416204 5300; E-mail: tmak@uhnresearch.ca

${ }^{5}$ These authors contributed equally to this work.

Keywords: glutathione; ROS; hemolysis; reticulocytosis; phosphatidylserine; eryptosis

Abbreviations: GCLC, glutamate-cysteine ligase catalytic subunit; GCLM, glutamate-cysteine ligase regulatory subunit; GSH, glutathione (reduced); GSSG, glutathione (oxidized); H\&E, hematoxylin and eosin stain; Hb, hemoglobin; PHZ, phenylhydrazine; PS, phosphatidylserine; RBC, red blood cell; ROS, reactive oxygen species; TBOOH, tert-butyl hydroperoxide

Received 17.12.12; revised 24.4.13; accepted 14.5.13; Edited by G Melino; published online 21.6.13
} 
$\mathrm{Hb}$ may accumulate and precipitate in the kidney tubules, thus impairing kidney function. ${ }^{12,13}$ Control of ROS in erythrocytes is thus very important for mammalian survival.

In this study, we used gene-targeted $\mathrm{gclm}^{-/-}$mice to explore the impact of a low capacity to defend against ROS on erythrocyte survival under resting conditions and conditions of significant oxidative stress.

\section{Results}

GCLM-deficient erythrocytes undergo enhanced cell death due to low antioxidant capacity. To determine the effects of GCLM deficiency on the capacity of erythrocytes to resist ROS, we first determined the intracellular glutathione level in erythrocytes isolated from $\mathrm{gclm}^{-/-}$mice. In line with a previous report, ${ }^{5}$ the intracellular glutathione content of erythrocytes from $\mathrm{gclm}^{-/-}$mice was dramatically reduced compared with $\mathrm{gclm}^{+/+}$mice (Figure 1a). In order to further characterize the ROS defense system in GCLM deficiency, we employed enzymatic tests to measure the activities of glutathione S-transferase, glutathione reductase, catalase and superoxide dismutase in erythrocytes from $\mathrm{gclm}^{+/+}$and $\mathrm{gclm}^{-1-}$ mice. As illustrated in Table 1, the enzymatic activities of glutathione S-transferase and catalase were significantly higher, whereas superoxide dismutase activity was significantly lower in $\mathrm{gclm}^{-/-}$red blood cells (RBCs). The activity of glutathione reductase was similar in erythrocytes from both genotypes (Table 1).

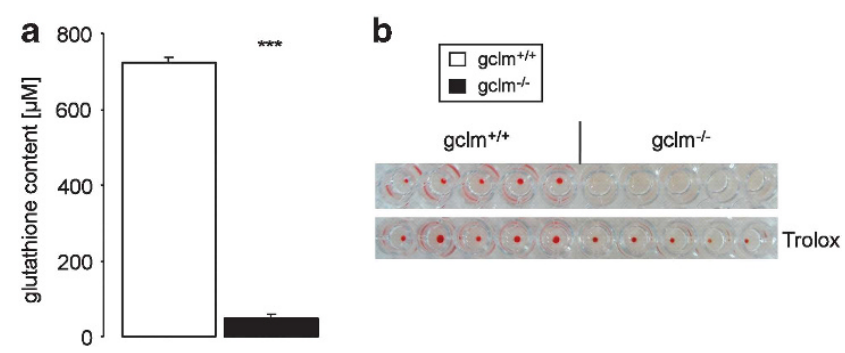

Figure 1 Erythrocytes isolated from $\mathrm{gclm}{ }^{-/-}$mice show low glutathione levels and are prone to cell death. (a) Cytosolic glutathione concentration in untreated erythrocytes isolated from resting $\mathrm{gclm}^{+/+}$and $\mathrm{gclm}^{-/-}$mice. Data are the mean \pm S.E.M. of $n=10$ mice/group. For all Figures, white bar $=\mathrm{gclm}^{+/+}$; black bar $=g \mathrm{clm}^{-/-} .{ }^{* *} P<0.001$ (Student's $t$-test). (b) Representative photographs of erythrocytes that were isolated from $\mathrm{gclm}+\mathrm{m}^{++}$and $\mathrm{gclm}{ }^{-1-}$ mice, and incubated at $37^{\circ} \mathrm{C}$ for $6-12 \mathrm{~h}$ (some variability in the extent of $\mathrm{gclm}^{-/-}$erythrocyte lysis is seen at this time point) in the absence (upper row) or presence (lower row) of $250 \mu \mathrm{M}$ Trolox (antioxidant)

Table 1 Enzymatic activities of glutathione S-transferase, glutathione reductase, catalase and superoxide dismutase in erythrocytes from $\mathrm{gclm}{ }^{+/+}$mice $(n=6)$ and $\mathrm{gclm}^{-1-}$ mice $(n=6)$

\begin{tabular}{lcc}
\hline Enzyme & $\begin{array}{c}\text { Activity in } \\
\text { gclm }^{+/+} \\
\text {RBCs }\end{array}$ & $\begin{array}{c}\text { Activity in } \\
\boldsymbol{g c l m}^{-/} \\
\text {RBCs }\end{array}$ \\
\hline Glutathione S-transferase $(\mathrm{nmol} / \mathrm{min} / \mathrm{ml})$ & $225 \pm 50$ & $356 \pm 26^{*}$ \\
Glutathione reductase $(\mathrm{nmol} / \mathrm{min} / \mathrm{ml})$ & $968 \pm 60$ & $1051 \pm 36$ \\
Catalase $(\mathrm{nmol} / \mathrm{min} / \mathrm{ml})$ & $5249 \pm 500$ & $9105 \pm 697^{\star *}$ \\
Superoxide dismutase $(\mathrm{U} / \mathrm{ml})$ & $742 \pm 60$ & $412 \pm 85^{*}$ \\
\hline
\end{tabular}

${ }^{\star} P<0.05 ;{ }^{\star \star} P<0.01$ (Student's $t$-test)
Next, we tested whether the dramatically reduced glutathione concentration affected the survival of $\mathrm{gclm}^{-/-}$ erythrocytes following an extended ex vivo incubation. Whereas prolonged incubation at $37^{\circ} \mathrm{C}$ without further treatment did not affect $\mathrm{gclm}^{+/+}$erythrocytes, $\mathrm{gclm}^{-/-}$ erythrocytes completely lysed (Figure 1b, upper panel). However, in the presence of the antioxidant Trolox, a derivative of vitamin $\mathrm{E}$, lysis of $\mathrm{gclm}^{-1-}$ erythrocytes could be completely prevented (Figure 1b, lower panel). This result demonstrates that enhanced death of $\mathrm{gclm}^{-1-}$ erythrocytes was indeed due to decreased antioxidant capacity.

Phenylhydrazine treatment causes massive hemolysis in GCLM-deficient mice. To determine the importance of GCLM for erythrocyte survival in vivo, we exposed $\mathrm{gclm}^{-1-}$ and $\mathrm{gclm} \mathrm{m}^{+/+}$mice to phenylhydrazine $(\mathrm{PHZ})$ at a dose of $0.07 \mathrm{mg} / \mathrm{g}$ b.w., which is commonly used to induce hemolytic anemia by generation of hydrogen peroxide. ${ }^{13-15}$ Twentyfour hours after $\mathrm{PHZ}$ treatment, $\mathrm{gclm}^{-1-}$ mice showed several fold more hemolysis than $\mathrm{gclm}^{+/+}$mice, as determined by measurements of free serum $\mathrm{Hb}$ (Figure 2a) and lactate dehydrogenase activity (Figure 2b). Moreover, $\mathrm{gclm}^{-/-}$mice lost more than twice as much weight compared with $\mathrm{gclm}^{+/+}$mice over a $24 \mathrm{~h}$ period post treatment (Figure 2c). This indicates an overall decreased capacity of $\mathrm{gclm}^{-/-}$mice to deal with oxidative stress insults compared with $\mathrm{gclm}^{+/+}$mice.

Injured erythrocytes accumulate in the spleens of GCLM-deficient mice upon treatment with PHZ. Our results so far indicate that imposing oxidative stress in vivo by $\mathrm{PHZ}$ treatment results in dramatically more death of $\mathrm{gclm}^{-/-}$than $\mathrm{gclm}^{+/+}$erythrocytes. Injured erythrocytes are mainly sequestered in the spleen where they are cleared from the bloodstream. ${ }^{16}$ Thus, we performed histological analyses of the spleens at $24 \mathrm{~h}$ post- $\mathrm{PHZ}$ treatment. As expected, greater number of erythrocytes were apparent in the spleens of $\mathrm{gclm}^{-/-}$mice, as evident from hematoxylin and eosin stain (H\&E) and iron staining (Figure 3a). Importantly, these cells showed significantly more externalized PS than erythrocytes in the spleens of PHZ-treated $\mathrm{gclm} \mathrm{m}^{+/+}$mice, underlining enhanced erythrocyte death in $\mathrm{gclm}^{-/-}$mice following induction of oxidative stress (Figure 3b). These data indicate that mice lacking GCLM suffer from increased erythrocyte damage upon oxidative stress with accumulation of the injured erythrocytes in the spleens of $\mathrm{gclm}^{-/-}$mice.

$\mathrm{Hb}$ precipitates in the kidney tubules of GCLM-deficient mice upon treatment with PHZ. Upon treatment with $\mathrm{PHZ}$, free serum $\mathrm{Hb}$ (Figure 2a) was the consequence of severe oxidative damage to erythrocytes, leading to the immediate destruction of cellular integrity and release of $\mathrm{Hb}$ before the injured cell could be cleared from the circulation. Free serum $\mathrm{Hb}$ is filtered through the glomeruli of the kidney ${ }^{17}$ and may accumulate and precipitate in renal tubules, thus reducing kidney function. ${ }^{13,18}$ We therefore analyzed the kidneys from $\mathrm{gclm}^{+/}$and $\mathrm{gclm}^{-/-}$mice at $24 \mathrm{~h}$ post-PHZ treatment. In line with dramatically more hemolysis in $\mathrm{gclm}^{-/-}$mice (Figure 2a), H\&E and iron stainings revealed significant 
a

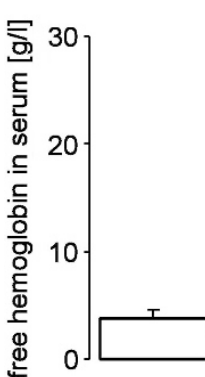

b

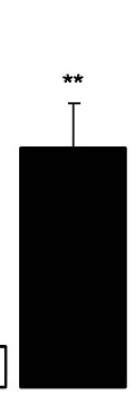

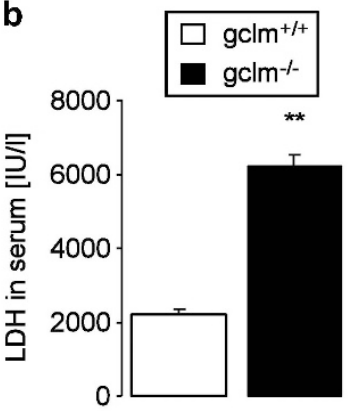

C

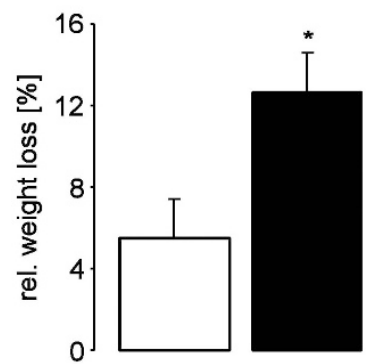

Figure 2 Massive hemolysis in gclm ${ }^{-1-}$ mice subjected to oxidative stress. (a) Concentration of free $\mathrm{Hb}$ in serum from $\mathrm{gclm} \mathrm{m}^{+/+}$and $\mathrm{gclm} \mathrm{m}^{-1-}$ mice at $24 \mathrm{~h}$ post-PHZ $\left(0.07 \mathrm{mg} / \mathrm{g}\right.$ b.w.) treatment. Data are the mean \pm S.E.M. of $n=4$ mice/group. For all Figures, white bars $=g c / m^{+/+} ;$black bars $=g c / m^{-/-}$. ${ }^{*} P<0.05 ;{ }^{* *} P<0.01$ (Student's t-test). (b) Lactate dehydrogenase activity in serum from $\mathrm{gclm}{ }^{+/+}$and $\mathrm{gclm} \mathrm{m}^{-/-}$mice at $24 \mathrm{~h}$ post-PHZ $(0.07 \mathrm{mg} / \mathrm{g}$ b.w.) treatment. Data are the mean \pm S.E.M. of $n=4$ mice/group. (c) Weight loss of gc/m ${ }^{+/+}$and $\mathrm{gclm}^{-/-}$mice following $24 \mathrm{~h}$ of PHZ $(0.07 \mathrm{mg} / \mathrm{g} \mathrm{b} . \mathrm{w}$.) treatment. Data were expressed relative to each mouse's starting weight. Results shown are the mean \pm S.E.M. of $n=4$ mice/group

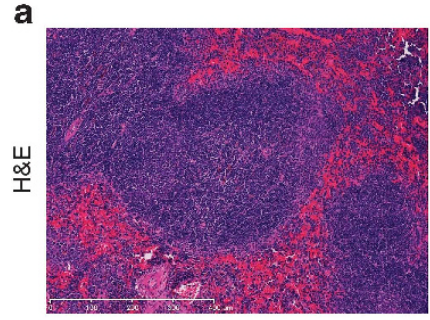

$\mathrm{gclm}^{+/+}$

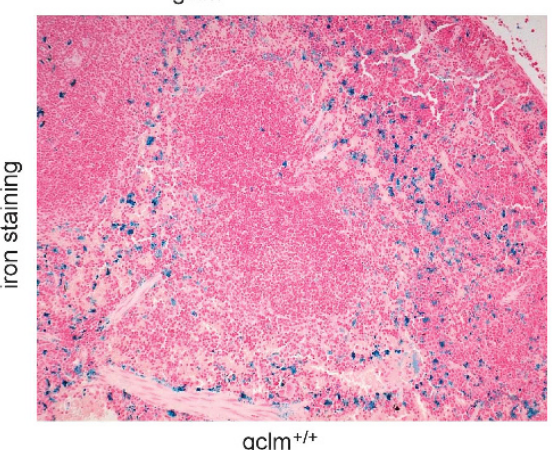

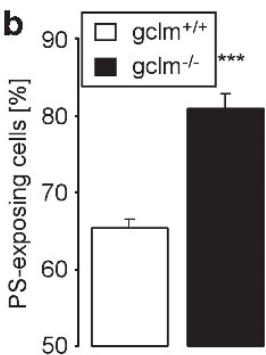

$\mathrm{gclm}^{-1}$

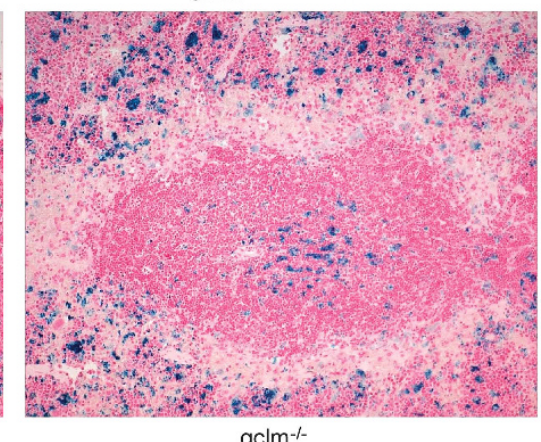

Figure 3 PS-exposing erythrocytes accumulate in the spleens of $g \mathrm{clm}{ }^{-/}$mice upon exposure to oxidative stress. (a) H\&E-stained sections (upper panels) and Prussian Blue-stained (to detect iron) sections (lower panels) of splenic tissue collected from $\mathrm{gclm}^{+/+}$(left) and gc/m ${ }^{-/-}$(right) mice at $24 \mathrm{~h} \mathrm{post-PHZ} \mathrm{(0.07} \mathrm{mg/g} \mathrm{b.w.)} \mathrm{treatment.}$ Results are representative of four mice/group. For all Figures, white bar $=g c / m^{+/+} ;$black bar $=g c / m^{-/-}$. ${ }^{\star \star *} P<0.001 \quad($ Student's $t$-test). (b) Percentage of PS-externalizing cells among total erythrocytes isolated from spleens of $\mathrm{gclm}^{+/+}$and $\mathrm{gclm} \mathrm{m}^{-/-} \mathrm{mice}$ at $24 \mathrm{~h}$ post-PHZ (0.07 mg/g b.w.) treatment. Data are the mean \pm S.E.M. of $n=4$ mice/group

hemosiderin in the renal tubules of $\mathrm{PHZ}$-treated $\mathrm{gclm}^{-1-}$ mice and virtually none in the tubules of $\mathrm{PHZ}$-treated $\mathrm{gclm}^{+/+}$mice (Figure 4a). To determine whether kidney function began to be affected by $\mathrm{Hb}$ precipitations in $\mathrm{PHZ}$-treated $\mathrm{gclm}^{-/-}$mice, we determined serum creatinine and urea levels at $24 \mathrm{~h}$ post $-\mathrm{PHZ}$ treatment. As expected, serum creatinine and urea levels were already elevated $24 \mathrm{~h}$ after induction of hemolysis in $\mathrm{gclm}^{-/-}$mice, confirming impairment of their renal function at this time point (Figure $4 \mathrm{~b}$ ). During the course of the experiment, $\mathrm{gclm}^{+/+}$ mice were able to recover from the oxidative stress insult and survived. Strikingly, $11 / 12 \mathrm{gclm}^{-/-}$mice died within 5 days of $\mathrm{PHZ}$ treatment (Figure 5).
Hemolysis is triggered in GCLM-deficient mice also upon treatment with low-dose PHZ. In order to study the antioxidant response under conditions of a lower oxidative stress insult, we performed a test with low-dose $\mathrm{PHZ}$ $(0.014 \mathrm{mg} / \mathrm{g}$ b.w.). Before injection of $\mathrm{PHZ}$ at this dose, the concentration of free $\mathrm{Hb}$ in serum from $\mathrm{gclm}^{+/+}$and $\mathrm{gclm}^{-1-}$ mice, which is indicative of hemolysis, was low and not significantly different between the genotypes (Figure 6a). Twenty-four hours after injection, the concentration of free $\mathrm{Hb}$ remained unchanged in $\mathrm{gclm} \mathrm{m}^{+/+}$mice but was significantly elevated in $\mathrm{gclm}^{-1-}$ mice (Figure 6a). Next, we characterized the redox status of the erythrocytes by measuring the ratio of the erythrocyte GSH concentration 


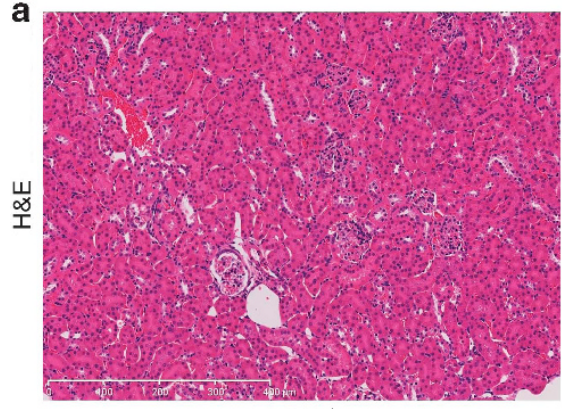

$\mathrm{gclm}^{+/+}$

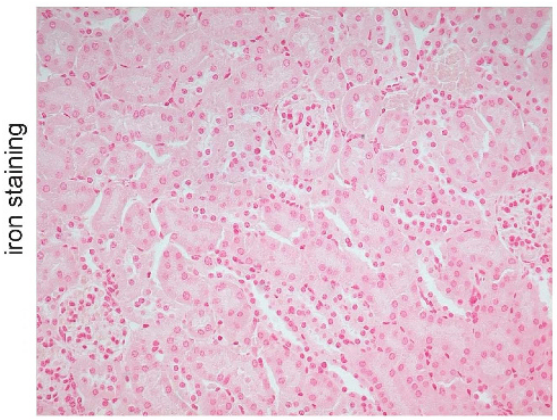

$\mathrm{gclm}^{+/+}$

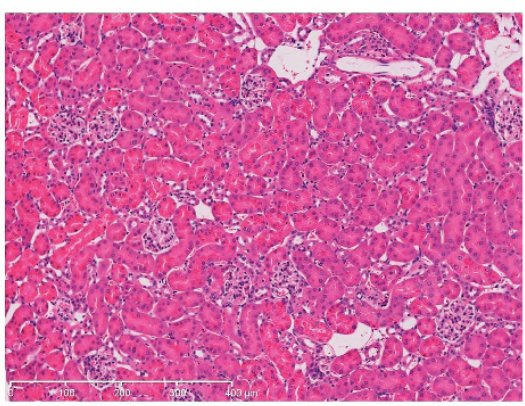

$\mathrm{gclm}^{-/-}$

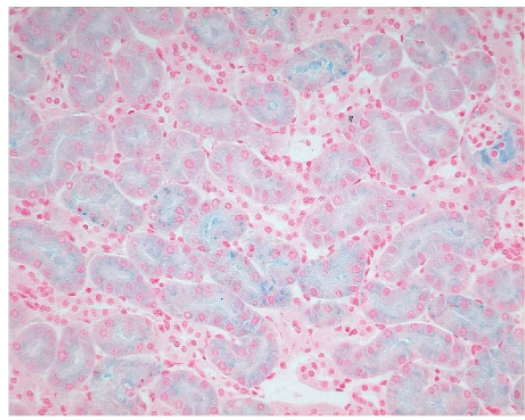

$\mathrm{gclm}^{-1-}$
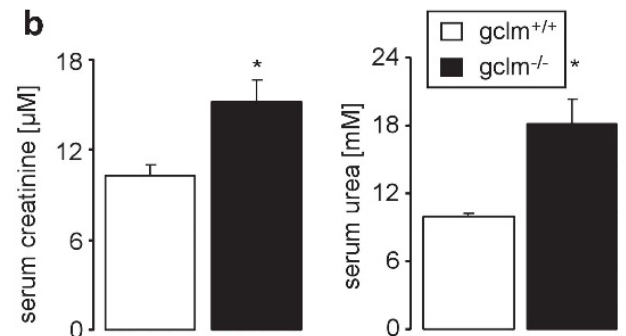

Figure 4 Hemosiderin in the kidneys and reduced kidney function of $\mathrm{gclm}^{-/-}$mice treated with PHZ. (a) H\&E-stained sections (upper panels) and Prussian Blue-stained (to detect iron) sections (lower panels) of renal tissue collected from $\mathrm{gclm}{ }^{+/+}$(left) and gclm ${ }^{-/}$(right) mice at $24 \mathrm{~h}$ post-PHZ (0.07 mg/g b.w.) treatment. Results are representative of four mice/group. For all Figures, white bars $=g \mathrm{clm}^{+/+}$; black bars $=\mathrm{gclm}^{-1-}$. ${ }^{\star} P<0.05$ (Student's $t$-test). (b) Concentrations of creatinine (left panels) and urea (right panels) in serum collected from $\mathrm{gclm}^{+/+}$and $\mathrm{gclm}^{-/-}$mice at $24 \mathrm{~h}$ post-PHZ $(0.07 \mathrm{mg} / \mathrm{g} \mathrm{b} . \mathrm{w}$.) treatment. Data are the mean \pm S.E.M. of $n=4 \mathrm{mice} /$ group

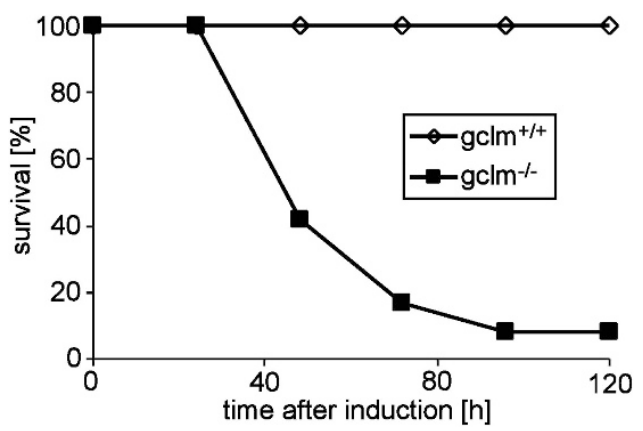

Figure 5 Survival of $\mathrm{gclm}^{-/-}$mice is dramatically reduced following treatment with PHZ. Survival curves of $\mathrm{gclm} \mathrm{m}^{+/+}$and $\mathrm{gclm}{ }^{-1-}$ mice $(n=12 /$ group) following $\mathrm{PHZ}(0.07 \mathrm{mg} / \mathrm{g}$ b.w.) treatment

over the GSSG concentration. Before $\mathrm{PHZ}$ treatment, the ratio tended to be lower in erythrocytes from $\mathrm{gclm}^{+/+}$ mice compared with $\mathrm{gclm}^{-/-}$erythrocytes (Figure $6 \mathrm{~b}$ ). $\mathrm{PHZ}$ treatment tended to reduce the ratio in erythrocytes from both genotypes (Figure 6b). The levels of both GSH and GSSG were lower in $\mathrm{gclm}^{-/-}$erythrocytes before and after $\mathrm{PHZ}$ treatment compared with $\mathrm{gclm}^{+/+}$erythrocytes. However, $\mathrm{PHZ}$ treatment significantly reduced GSH levels only in $\mathrm{gclm}^{-/-}$erythrocytes (Figure $6 \mathrm{~b}$ ). In contrast to $\mathrm{PHZ}$ at high dose, all $\mathrm{gclm}^{+/+}(n=4)$ and $\mathrm{gclm}^{-/-}$mice $(n=4)$ survived the experiment for at least 1 week. Our in vivo data clearly indicate massive hemolysis in $\mathrm{gclm}^{-1-}$ mice subjected to both high- and low-oxidative stress insults.

GCLM-deficient erythrocytes are more prone to $\mathrm{Ca}^{2+}$-dependent suicidal cell death ex vivo. In order to elucidate whether suicidal erythrocyte death is involved as a consequence of the higher susceptibility of $\mathrm{gclm}^{-1-}$ erythrocytes to ROS-induced cell damage, the percentage of erythrocytes exposing membrane PS was measured. Significantly more erythrocytes from $\mathrm{gclm}^{-/}$mice compared with $\mathrm{gclm}^{+/+}$mice externalized PS at their cell surface although the total percentage of PS-exposing erythrocytes remained low in both genotypes (Figure $7 \mathrm{a}$ ). This result 

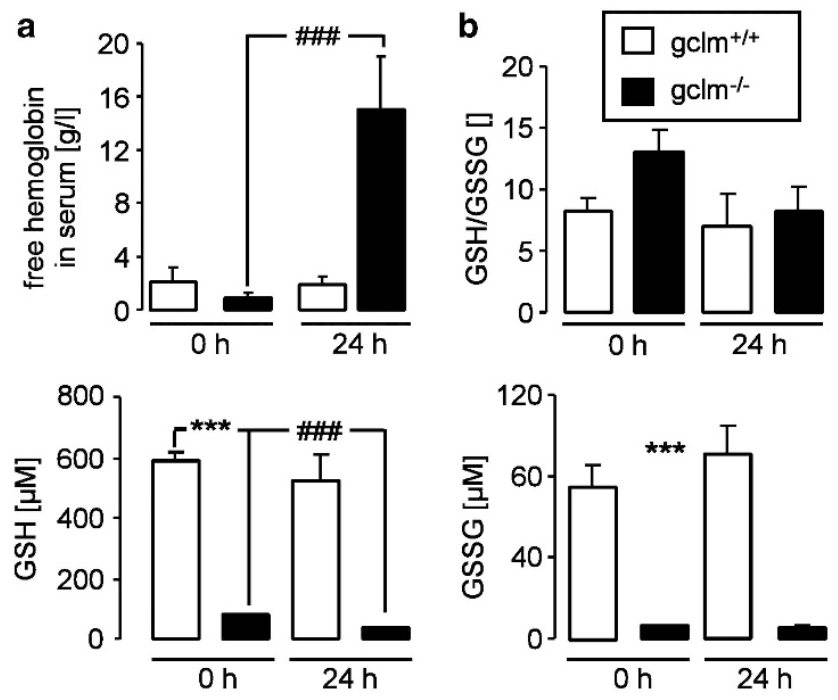

Figure 6 Hemolysis is triggered in GCLM-deficient mice also upon treatment with low-dose PHZ. (a) Concentration of free $\mathrm{Hb}$ in serum from $\mathrm{gclm}^{+/+}$and $\mathrm{gclm}{ }^{-1-}$ mice before (left bars) and at $24 \mathrm{~h}$ post-PHZ (right bars; $0.014 \mathrm{mg} / \mathrm{g} \mathrm{b.w}$.) treatment. Data are the mean \pm S.E.M. of $n=3-4$ mice/group. For all Figures, white bars $=g c / m^{+/+}$; black bars $=g c / m^{-/-} .{ }^{* * *}$ or ${ }^{\# \#} P<0.001$; Student's $t$ test). (b) GSH/GSSG ratio (upper panel), concentration of GSH (lower left panel) and concentration of GSSG (lower right panel) in erythrocytes from $\mathrm{gclm}^{+/+}$and $\mathrm{gclm}^{-1-}$ mice before (left bars) and at $24 \mathrm{~h}$ post-PHZ (right bars; $0.014 \mathrm{mg} / \mathrm{g} \mathrm{b.w}$.) treatment. Data are the mean \pm S.E.M. of $n=4$ mice/group

indicates slightly enhanced cell death of $\mathrm{gclm}^{-/-}$erythrocytes, presumably as the consequence of lower antioxidant capacity.

To explore the capability of $\mathrm{gclm}^{-/-}$and $\mathrm{gclm}^{+/+}$ erythrocytes to resist additional oxidative stress in vitro, we incubated the cells for $30 \mathrm{~min}$ ex vivo at $37^{\circ} \mathrm{C}$ in physiological solution. We found that merely incubating untreated $\mathrm{gclm}^{-1-}$ erythrocytes resulted in a higher percentage of PS-externalizing cells than parallel incubation of $\mathrm{gclm}^{+/+}$erythrocytes (Figure $7 \mathrm{~b}$ ). Moreover, when $\mathrm{gclm}^{-1-}$ erythrocytes were subjected to additional ROS in the form of a 30 min incubation with $0.3 \mathrm{mM}$ tert-butyl hydroperoxide $(\mathrm{TBOOH})$ at $37^{\circ} \mathrm{C}$, again significantly more PS exposure occurred in $\mathrm{gclm}^{-/-}$than in $\mathrm{gclm}^{+/+}$erythrocytes (Figures $7 \mathrm{~b}$ and $\mathrm{c}$ ), pointing to a reduced resistance of $\mathrm{gclm} \mathrm{m}^{-/-}$erythrocytes to oxidative stress. Oxidative stress-mediated erythrocyte death with subsequent PS externalization has been shown to be dependent on an increase in the cytosolic $\mathrm{Ca}^{2+}$ concentration. ${ }^{11}$ Hence, we estimated the cytosolic $\mathrm{Ca}^{2+}$ concentration of $\mathrm{gclm}^{-1-}$ and $\mathrm{gclm}^{+/+}$erythrocytes using Fluo3 fluorescence in FACS analysis. Consistent with their enhanced susceptibility to death, $\mathrm{gclm} \mathrm{m}^{-/-}$erythrocytes incubated for $30 \mathrm{~min}$ in the absence of treatment indeed displayed more Fluo3 fluorescence than $\mathrm{gclm} \mathrm{m}^{+/+}$erythrocytes, indicating elevated cytosolic $\mathrm{Ca}^{2+}$ concentration (Figure 7d).

To specify the role of ROS for the erythrocyte $\mathrm{Ca}^{2+}$ concentration, we incubated the erythrocytes at $37^{\circ} \mathrm{C}$ without

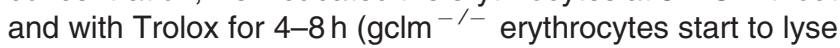
typically after a 4-8 h incubation with some variability) and quantified intracellular $\mathrm{Ca}^{2+}$ using Fluo3 before complete lysis of $\mathrm{gclm}^{-/-}$erythrocytes. We found that the normalized
Fluo3 fluorescence intensity (as a measure of intracellular $\mathrm{Ca}^{2+}$ ) was significantly higher in $\mathrm{gclm}^{-/-}$erythrocytes compared with $\mathrm{gclm}^{+/+}$erythrocytes (Figure 7e). Incubation with $250 \mu \mathrm{M}$ Trolox significantly reduced Fluo3 fluorescence in $\mathrm{gclm}^{-/-}$erythrocytes (Figure 7e). In order to study the significance of $\mathrm{Ca}^{2+}$ for PS exposure, we carried out incubations without or with Trolox in the presence and absence of extracellular $\mathrm{Ca}^{2+}$ and determined the percentage of PS-exposing cells before complete lysis of $\mathrm{gclm}^{-1-}$ erythrocytes. After a $4-8 \mathrm{~h}$ incubation at $37^{\circ} \mathrm{C}$, significantly more $\mathrm{gclm}^{-1-}$ erythrocytes exposed PS in the presence of extracellular $\mathrm{Ca}^{2+}$ (Figure 7f). Addition of $250 \mu \mathrm{M}$ Trolox significantly reduced the percentage of PS-exposing $\mathrm{gclm}^{-/-}$ erythrocytes. Importantly, the absence of extracellular $\mathrm{Ca}^{2+}$ was similarly capable of blunting PS exposure of $\mathrm{gclm}^{-1-}$ erythrocytes (Figure 7f). In both the absence of extracellular $\mathrm{Ca}^{2+}$ and the presence of $250 \mu \mathrm{M}$ Trolox, PS exposure was minimal in $\mathrm{gclm}^{-/-}$erythrocytes (Figure 7f).

GCLM-deficient mice ramp up their generation of erythrocytes. In order to study whether the greater susceptibility of $\mathrm{gclm}^{-/-}$erythrocytes to death in vitro was mimicked in vivo, we analyzed blood counts from wild-type and knockout mice without any further treatment. Indeed, blood samples from $\mathrm{gclm}^{-/-}$mice contained marginally but significantly more reticulocytes than samples from $\mathrm{gclm}^{+/+}$ mice (Figure 8a). Surprisingly, under resting conditions without additional oxidative stress, $\mathrm{gclm}^{-/-}$mice were evidently able to balance the elevated death rate of their erythrocytes with marginally enhanced reticulocyte generation, as their overall erythrocyte numbers and properties were unchanged (Figure 8b).

Our ex vivo examinations showed that the enhanced death of $\mathrm{gclm} \mathrm{m}^{-/-}$erythrocytes was due to ROS because their lysis could be inhibited by Trolox. In vivo, however, the greater susceptibility of $\mathrm{gclm}^{-/-}$erythrocytes to hemolysis did not translate into anemia as long as the mice are not exposed to additional oxidative stress. Rather, under resting conditions without additional oxidative stress, the mutant animals were able to survive by slightly ramping up their generation of new erythrocytes.

\section{Discussion}

The present study explored for the first time the role of GCLM deficiency on erythrocyte survival, in vitro and in vivo, under both conditions of normal oxidative stress and conditions of increased ROS.

$\mathrm{Gclm}^{-/-}$mice are an important model of a continuously increased oxidative stress environment due to decreased glutathione production. ${ }^{4}$ Although massively depleted of glutathione, the major antioxidant in most tissues, $\mathrm{gclm}^{-1-}$ mice are seemingly healthy and normal. ${ }^{3-5}$ In line with previous reports, we found that the glutathione concentration of erythrocytes from $\mathrm{gclm}^{-1-}$ mice was $<10 \%$ of the concentration of erythrocytes from $\mathrm{gclm}^{+/+}$mice. ${ }^{3,5}$ Glutathione is a major antioxidant of erythrocytes and reduces their considerable oxidative burden, which arises from their role as $\mathrm{O}_{2}$-transporting cells. ${ }^{19}$ 


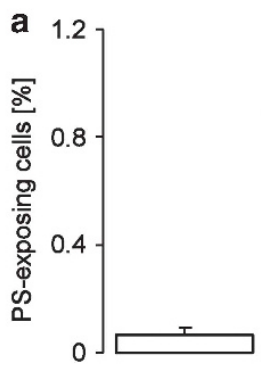

C

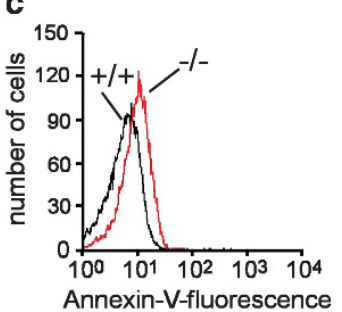
[rel units]
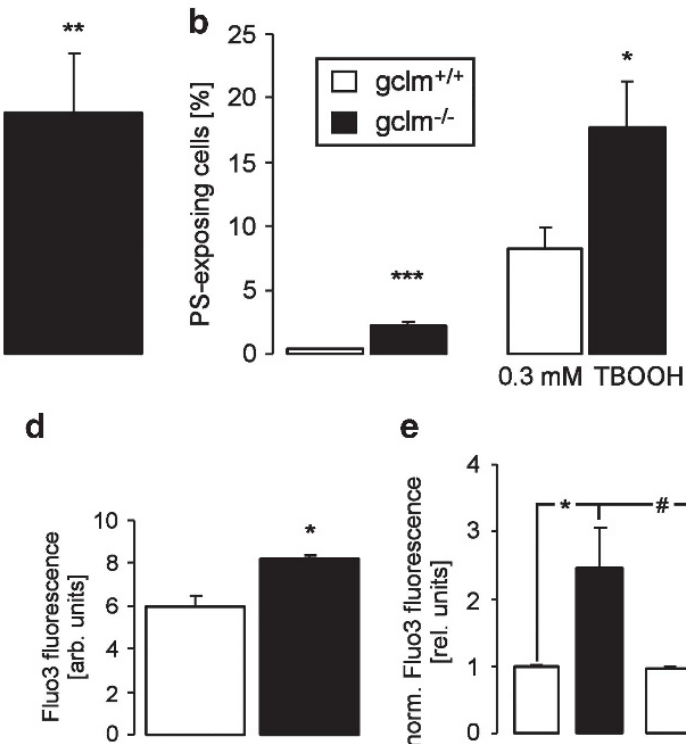

e

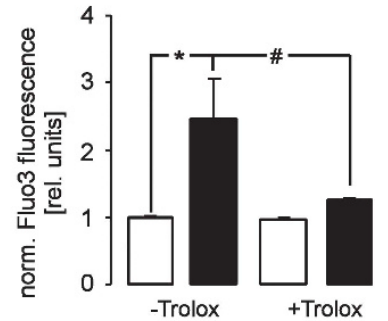

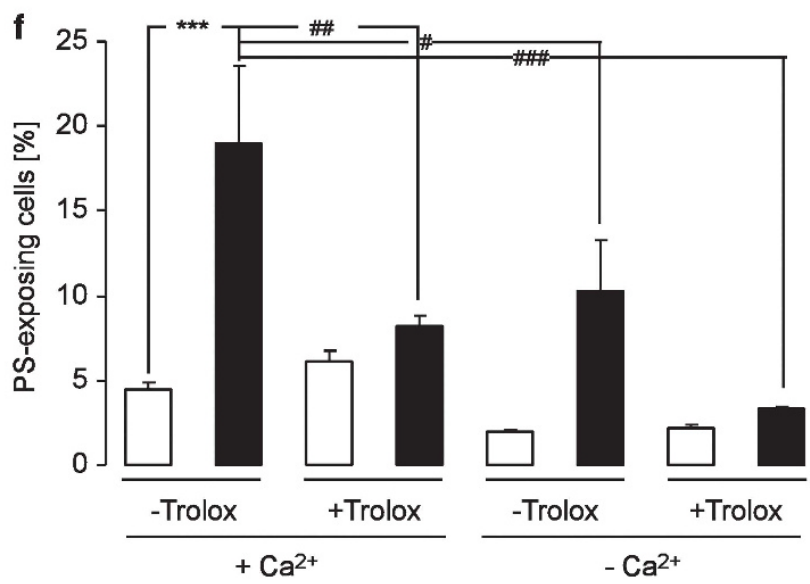

Figure 7 Ex vivo, gclm ${ }^{-1-}$ erythrocytes die of $\mathrm{Ca}^{2+}$-induced cell death. (a) Percentage of total erythrocytes from $\mathrm{gclm} \mathrm{m}^{+/+}$and $\mathrm{gclm}{ }^{-/-}$mice that externalized PS. Erythrocytes were stained to detect PS immediately upon blood collection. Data are the mean \pm S.E.M. of $n=5$ mice/group. For all Figures, white bars $=g c / m^{+/+}$; black bars $=g c / m^{-1-}$. ${ }^{*}$ or ${ }^{\#} P<0.05$; ${ }^{* *}$ or ${ }^{\# \#} P<0.01$; ${ }^{* * *}$ or ${ }^{\# \# \#} P<0.001$ (Student's $t$-test). (b) Percentage of total erythrocytes from $g c / m^{+1+}$ and $g c / m^{-1-}$ mice that externalized PS after incubation at $37^{\circ} \mathrm{C}$ for $30 \mathrm{~min}$ in vitro in the absence of treatment (left), or in the presence of $0.3 \mathrm{mM} \mathrm{TBOOH}$ (right). Data are the mean \pm S.E.M. of $n=8$ mice/group (analysis of variance). (c) Representative original histogram displaying Annexin $V$ fluorescence of the erythrocytes in (b, right); that is, $\mathrm{gclm}^{+/+}$and $\mathrm{gclm}{ }^{-/-}$ erythrocytes that were incubated at $37^{\circ} \mathrm{C}$ for 30 min with $0.3 \mathrm{mM} \mathrm{TBOOH}$. (d) Cytosolic $\mathrm{Ca}^{2+}$ concentration as determined by Fluo3 fluorescence of erythrocytes that were isolated from $\mathrm{gclm} \mathrm{m}^{+/+}$and $\mathrm{gclm}{ }^{-1-}$ mice and incubated at $37^{\circ} \mathrm{C}$ for $30 \mathrm{~min}$ without treatment. Data are expressed in arbitrary units and are the mean \pm S.E.M. of $n=3$ mice/group. (e) Cytosolic $\mathrm{Ca}^{2+}$ concentration as determined by Fluo3 fluorescence of erythrocytes that were isolated from $\mathrm{gclm}{ }^{+/+}$and $\mathrm{gclm}{ }^{-1-}$ mice and incubated at $37^{\circ} \mathrm{C}$ for 4-8 without treatment (left bars) or with $250 \mu \mathrm{M}$ Trolox (right bars). Data are normalized fluorescence intensities expressed in relative units and are the mean \pm S.E.M. of $n=10$ experiments with erythrocytes from eight mice/group (analysis of variance). (f) Percentage of total erythrocytes from $\mathrm{gclm}^{+/+}$and gc/m ${ }^{-1-}$ mice that externalized PS after incubation at $37^{\circ} \mathrm{C}$ for $4-8 \mathrm{~h}$ in vitro in the presence $\left(+\mathrm{Ca}^{2+}\right)$ or absence $\left(-\mathrm{Ca}^{2+}\right)$ of extracellular $\mathrm{Ca}^{2+}$ without $\left(-\mathrm{Trolox}^{2}\right.$ or with $250 \mu \mathrm{M}$ Trolox ( + Trolox). Data are the mean \pm S.E.M. of $n=10$ experiments with erythrocytes from eight mice/group (analysis of variance)

When erythrocytes are exposed to ROS to an extent that exceeds their ROS-scavenging capacity, they may execute a program of suicidal cell death or eryptosis, which ultimately results in externalization of membrane PS. ${ }^{11}$ Erythrocytes express $\mathrm{Ca}^{2+}$-permeable cation channels, which are activated by oxidative stress. ${ }^{20}$ The $\mathrm{Ca}^{2+}$ entry through those channels increases cytosolic $\mathrm{Ca}^{2+}$ activity, leading to triggering of cell membrane scrambling. ${ }^{11}$ Moreover, $\mathrm{Ca}^{2+}$ activates $\mathrm{Ca}^{2+}$-sensitive $\mathrm{K}^{+}$channels with subsequent hyperpolarization, exit of $\mathrm{Cl}^{-}$with osmotically obliged water and thus cell shrinkage. ${ }^{21}$ Cell membrane scrambling and cell shrinkage are hallmarks of eryptosis, the suicidal death of erythrocytes. ${ }^{12}$ The oxidant-sensitive $\mathrm{Ca}^{2+}$-permeable cation channels are in addition permeable to $\mathrm{Na}^{+},{ }^{20}$ thus allowing the entry of $\mathrm{Na}^{+}$, which eventually leads to cell swelling and hemolysis. It should be noted, however, that live cells may also expose some PS at the surface, especially under conditions triggering increases in cytosolic $\mathrm{Ca}^{2+}$ concentration.

A 30 min ex vivo incubation of $\mathrm{gclm}^{-/-}$erythrocytes in a physiological solution resulted in significantly more PS exposure than the respective incubation of $\mathrm{gclm}^{+/+}$ 

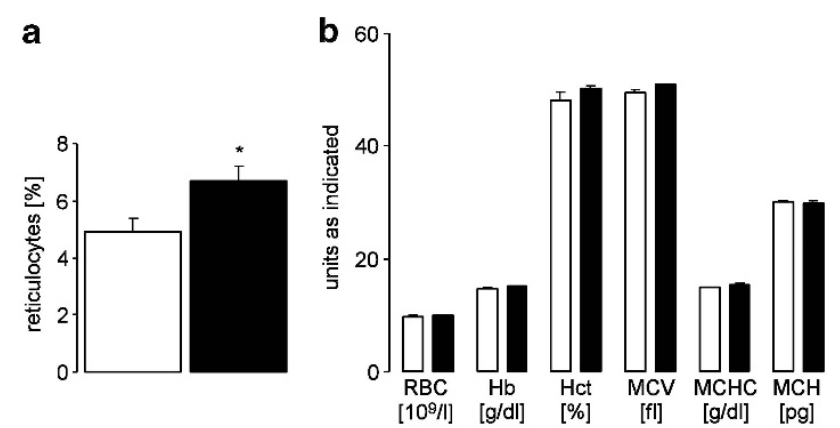

Figure $8 \mathrm{Gclm}^{-1-}$ mice exhibit reticulocytosis but show an otherwise unaltered blood count. (a) Percentage of total blood cells that were reticulocytes in resting $\mathrm{gclm}^{+/+}$and $\mathrm{gclm}^{-1-}$ mice. Data are the mean \pm S.E.M. of $n=8$ mice/ group. For all Figures, white bars $=g \mathrm{clm}{ }^{+/+}$; black bars $=g \mathrm{clm}{ }^{-1-}$. ${ }^{*} P<0.05$ (Student's $t$-test). (b) Standard hematological parameters in resting $\mathrm{gclm}^{+/+}$and $\mathrm{gclm}^{-1-}$ mice. Data are the mean \pm S.E.M. and are expressed as indicated ( $n=3-4$ mice/group)

erythrocytes, emphasizing the minimal ROS-scavenging capacity of $\mathrm{gclm}^{-/-}$erythrocytes. Under conditions of additional oxidative stress, the difference between $\mathrm{gclm}^{-/-}$ and $\mathrm{gclm} \mathrm{m}^{+/+}$erythrocytes in PS externalization became even larger (Figure 7b). Oxidative stress has been shown to induce erythrocyte PS exposure through an increase in the cytosolic $\mathrm{Ca}^{2+}$ concentration. ${ }^{11}$ Consistent with augmented PS externalization, $\mathrm{gclm} \mathrm{m}^{-/-}$erythrocytes indeed exhibited increased cytosolic $\mathrm{Ca}^{2+}$ concentration as evident from increased Fluo3 fluorescence. The elevated cytosolic $\mathrm{Ca}^{2+}$ of $\mathrm{gclm}^{-/-}$ erythrocytes was at least in part the consequence of ROS, as Trolox did not only prevent erythrocyte lysis but also decreased the cytosolic $\mathrm{Ca}^{2+}$ concentration of $\mathrm{gclm}^{-/-}$ erythrocytes. Moreover, PS exposure of $\mathrm{gclm}^{-1-}$ erythrocytes was $\mathrm{Ca}^{2+}$-dependent, as incubation for an extended period in $\mathrm{Ca}^{2+}$-free solution, not long enough to cause complete $\mathrm{gclm}^{-/-}$erythrocyte lysis, significantly attenuated annexin $\mathrm{V}$-binding.

In vivo, erythrocyte PS externalization is considered an 'eatme' signal, which may be recognized by macrophages by their PS receptors. ${ }^{22}$ Thus, PS-exposing erythrocytes are normally rapidly cleared from the circulation before they lyse and release $\mathrm{Hb} .^{12,23}$ In the case of an ex vivo incubation (in the absence of macrophages), however, $\mathrm{gclm}^{-1-}$ erythrocytes lysed, as the oxidative damage obviously became too detrimental to maintain cellular integrity. Importantly, cell death of $\mathrm{gclm}^{-/-}$erythrocytes was indeed solely due to increased ROS levels as the antioxidant Trolox fully prevented their lysis.

When stained directly after blood collection, erythrocytes from $\mathrm{gclm}^{-/-}$mice externalized marginally more PS, indicating slightly enhanced erythrocyte death also in vivo. Despite their very low antioxidant capacity, however, the total percentage of PS-exposing erythrocytes remained remarkably low in $\mathrm{gclm}^{-/-}$mice. Consistent with a low percentage of PS-externalizing erythrocyte, RBC numbers and properties were not different in unstressed $\mathrm{gclm}^{-/-}$and $\mathrm{gclm}^{+/+}$mice. Only a small but significant increase in reticulocytosis in $\mathrm{gclm}^{-/-}$mice may indicate that formation of new erythrocytes was mildly ramped up to fully compensate for a slightly increased erythrocyte death rate. This result may indicate slightly increased erythrocyte turnover in unstressed mice. In other words, oxidative stress was too low to cause overt anemia of $\mathrm{gclm}^{-/-}$mice in the absence of additional stressors. In addition, apart from glutathione, other antioxidant mechanisms are expressed in erythrocytes, which protect from oxidative damage even in glutathione deficiency. ${ }^{24}$ Among those are superoxide dismutase and catalase. $^{25}$ We found increased catalase and decreased superoxide dismutase activity in RBCs from $\mathrm{gclm}^{-/-}$mice. The operation of those additional mechanisms apparently also ensured survival of $\mathrm{gclm}{ }^{-1-}$ erythrocytes in animals not exposed to additional oxidative stress. It has been shown that erythrocyte catalase, but not superoxide dismutase, protects other cells from oxidative damage. ${ }^{26}$ It is intriguing to speculate that increased catalase activity in $\mathrm{gclm}^{-/}$ erythrocytes is a compensatory mechanism to protect not only the RBCs itself but also other cells in the organism from the consequences of glutathione deficiency. Enhanced activity of glutathione S-transferase may be another strategy to protect $\mathrm{gclm}^{-/-}$RBCs from cell death in glutathione deficiency, as erythrocyte glutathione S-transferase deficiency has been linked to hemolytic anemia. ${ }^{27}$

When we subjected the mice to additional oxidative stress in the form of a single $\mathrm{PHZ}$ injection $(0.07 \mathrm{mg} / \mathrm{g} \mathrm{b.w.)}$, the residual antioxidant capacity was immediately insufficient to alleviate ROS-induced damage of $\mathrm{gclm}^{-/-}$erythrocytes as apparent from a sixfold higher free serum $\mathrm{Hb}$ concentration in $\mathrm{gclm}^{-1-}$ mice. Consequently, $\mathrm{Hb}$ and hemosiderin accumulation occurred in the renal tubules of $\mathrm{gclm}^{-/-}$mice $24 \mathrm{~h}$ after treatment. This coincided with a decline in kidney function of $\mathrm{gclm}^{+/+}$mice, as documented by increased serum creatinine and urea. Injured erythrocytes that do not immediately lyse due to oxidative damage accumulate in the spleen. Again, we observed more sequestered erythrocytes and, among those, more PS-externalizing cells in the spleens of $\mathrm{gclm}^{-1-}$ mice than in those of $\mathrm{gclm}^{+/+}$mice. This result again demonstrates a strikingly more massive destruction of $\mathrm{gclm}^{-/-}$ erythrocytes compared with $\mathrm{gclm}^{+/+}$erythrocytes.

All $\mathrm{gclm}^{+/+}$mice fully recovered from $\mathrm{PHZ}(0.07 \mathrm{mg} / \mathrm{g}$ b.w.)-induced oxidative damage. In contrast, more than $90 \%$ of $\mathrm{gclm} \mathrm{m}^{-/-}$mice died within 5 days after treatment, indicating that finally fatal erythrocyte death was the inevitable consequence of glutathione deficiency under conditions of increased oxidative stress. When subjected to low-dose $\mathrm{PHZ}$ treatment $(0.014 \mathrm{mg} / \mathrm{g}$ b.w.), no obvious hemolysis was observed in $\mathrm{gclm}+/+$ mice. $\mathrm{Gclm}^{-/-}$mice again suffered from hemolysis, albeit milder, and that did not affect their survival.

Erythrocytes are the most abundant cell type in the mammalian body. As circulating cells, they provide antioxidant defense capacity also to other organs and tissues. ${ }^{24}$ Accordingly, they have been considered as 'mobile freeradical scavengers'. ${ }^{24}$ When severely damaged or fully lysed upon $\mathrm{PHZ}$ treatment, $\mathrm{gclm} \mathrm{m}^{-/-}$erythrocytes failed to provide protection from oxidative damage also to other organs, a mechanism likely to contribute to the fatal outcome in GCLM deficiency.

Apart from human GCLM polymorphisms that lead to lower glutathione levels, ${ }^{6,7}$ glucose-6-phosphate dehydrogenase deficiency results in lower resistance of erythrocytes to 
oxidative stress, as it impairs the regeneration of reduced $\mathrm{GSH}^{28}$ Glucose-6-phosphate dehydrogenase deficiency affects 400 million people worldwide and is one of the most common inherited diseases. ${ }^{28}$ With striking similarity to $\mathrm{gclm}^{-/-}$mice, humans with glucose-6-phosphate dehydrogenase deficiency are often asymptomatic as long as they are unstressed. ${ }^{28}$ When exposed to additional oxidative stress such as in the form of fava beans they also develop hemolytic anemia. ${ }^{28}$ In vitro oxidative stress increases PS exposure to a significantly larger extent in glucose-6-phosphate dehydrogenase-deficient erythrocytes than in normal erythrocytes. ${ }^{29}$ Upon exposure to $\mathrm{PHZ}, \mathrm{gclm}^{-/-}$mice apparently developed those severe symptoms which people with severe glucose6-phosphate deficiency would be likely to show in a similar situation.

In summary, our data demonstrate that low erythrocyte glutathione levels due to GCLM deficiency are well tolerated by mice housed under resting conditions where oxidative stress is minimal. However, when ROS accumulations are high, mice with GCLM deficiency undergo massive hemolysis that has a fatal outcome. Thus, in a real world filled with oxidative insults, GCLM is essential for mammalian survival.

\section{Materials and Methods}

Mice. GCLM-deficient $\left(\mathrm{gclm} \mathrm{m}^{-/-}\right)$and wild-type $\left(\mathrm{gclm} \mathrm{m}^{+/+}\right)$mice (8-16-weekold males) were described previously ${ }^{5}$ and housed in the animal facility of the Princess Margaret Hospital (Toronto, Ontario, Canada) under standard conditions. For induction of ROS in vivo, mice received one i.p. injection of $0.07 \mathrm{mg} / \mathrm{g} \mathrm{b.w}$. (high-dose test) or $0.014 \mathrm{mg} / \mathrm{g}$ b.w. (low-dose test) PHZ (Sigma-Aldrich, Oakville, Ontario, Canada). Animal experiments were approved by the Animal Care and Use Committee of the University Health Network (Toronto, Ontario, Canada).

Erythrocytes and serum. Under light anesthesia with isoflurane, blood was drained from the retro-orbital plexus of the mice with heparinized capillaries and collected in heparin-coated tubes for erythrocyte analysis or in serum tubes for serum analysis (BD Biosciences, Mississauga, ON, Canada).

ELISA. To measure the intracellular glutathione concentration in erythrocytes, erythrocytes from $60 \mu \mathrm{l}$ full blood were analyzed. The erythrocytes were lysed in water, the lysate was deproteinated and the glutathione concentration was measured using the Glutathione Assay Kit (Cayman Chemicals, Ann Arbor, MI, USA) or using the Bioxytech GSH/GSSG-412 kit (Percpio Biosciences, Burlingame, CA, USA) according to the provided manual. The concentration of free serum $\mathrm{Hb}$ was measured using an ELISA Kit (Kamiya, Seattle, WA, USA). The erythrocyte activities of glutathione S-transferase, glutathione reductase, catalase and superoxide dismutase were measured with enzyme assay kits from Cayman Chemicals. To ascertain comparability between the genotypes, erythrocytes were pelleted and the same volume of erythrocyte pellet used for the assays.

Flow cytometry. To determine PS exposure, erythrocytes were stained with Annexin-V-FITC (1:1000; BD Biosciences) in incubation buffer $(125 \mathrm{mM}$ $\mathrm{NaCl}, 5 \mathrm{mM} \mathrm{KCl}, 5 \mathrm{mM}$ glucose, $32 \mathrm{mM}$ HEPES, $1 \mathrm{mM} \mathrm{Mg}_{2} \mathrm{SO}_{4}, 1 \mathrm{mM} \mathrm{CaCl} 2$ $\mathrm{pH}$ 7.4) plus an additional $4 \mathrm{mM} \mathrm{CaCl} 2$ for $15 \mathrm{~min}$ at $37^{\circ} \mathrm{C}$ and analyzed on a FACS Calibur (BD Biosciences) in fluorescence channel FL-1. To estimate the intracellular $\mathrm{Ca}^{2}$ concentration erythrocytes were stained with Fluo3/AM (Invitrogen, Burlington, Ontario, Canada; 1:1000 in incubation buffer) for $15 \mathrm{~min}$ at $37^{\circ} \mathrm{C}$. Reticulocyte numbers were determined with RETIC-count (BD Biosciences) according to the provided protocol. For some experiments, erythrocytes from $4 \mu \mathrm{l}$ blood were incubated for $30 \mathrm{~min}-12 \mathrm{~h}$ (as indicated) at $37^{\circ} \mathrm{C}$ in $1000 \mu$ incubation buffer with or without $0.3 \mathrm{mM} \mathrm{TBOOH}$ (Sigma-Aldrich), an oxidative stress stimulus; or with or without $250 \mu \mathrm{M}$ Trolox (Roche, Mannheim, Germany), an antioxidant derived from vitamin $\mathrm{E}$. In $\mathrm{Ca}^{2+}$-free incubation buffer, $1 \mathrm{mM} \mathrm{CaCl}_{2}$ was substituted for $1 \mathrm{mM}$ EGTA.
Blood count and chemistry. Blood cell counts, measurements of lactate dehydrogenase activity, and determinations of serum creatinine and urea levels were performed according to veterinary standards by IDEXX (Markham, Ontario, Canada).

Histology. Mouse kidneys and spleens were formalin fixed $\left(48 \mathrm{~h}, 4^{\circ} \mathrm{C}\right)$ and paraffin embedded. Sections of paraffin-embedded tissues were stained with $\mathrm{H} \& \mathrm{E}$ or Prussian Blue to detect iron according to standard protocols.

Statistics. Data are expressed as arithmetic means \pm S.E.M., and statistical analyses were performed using Student's $t$-test unless otherwise stated. $P<0.05$ was considered statistically significant.

\section{Conflict of Interest}

The authors declare no conflict of interest.

Acknowledgements. We thank Dr. B Hershenfield for technical support and Dr. M Saunders for scientific editing. M.F. was supported by a stipend from Deutscher Akademischer Austauschdienst (DAAD) and by the Deutsche Forschungsgemeinschaft (DFG FO 695/1-1)

\section{Author Contributions}

MF, ISH, FL and TWM designed the research. MF, ISH, AE and RJ performed the experiments. TJK provided $\mathrm{gcl} / \mathrm{m}^{-1-}$ mice and edited the manuscript. MF, FL and TWM wrote the manuscript.

1. Beutler E, Moroose R, Kramer L, Gelbart T, Forman L. Gamma-glutamylcysteine synthetase deficiency and hemolytic anemia. Blood 1990; 75: 271-273.

2. Pastore A, Federici G, Bertini E, Piemonte F. Analysis of glutathione: implication in redox and detoxification. Clin Chim Acta 2003; 333: 19-39.

3. Yang Y, Dieter MZ, Chen Y, Shertzer HG, Nebert DW, Dalton TP. Initial characterization of the glutamate-cysteine ligase modifier subunit $\mathrm{GcIm}(-/-)$ knockout mouse. Novel model system for a severely compromised oxidative stress response. J Biol Chem 2002; 277 : 49446-49452.

4. Cole TB, Giordano G, Co AL, Mohar I, Kavanagh TJ, Costa LG. Behavioral characterization of GCLM-knockout mice, a model for enhanced susceptibility to oxidative stress. J Toxicol 2011; 2011: 157687.

5. McConnachie LA, Mohar I, Hudson FN, Ware CB, Ladiges WC, Fernandez C et al. Glutamate cysteine ligase modifier subunit deficiency and gender as determinants of acetaminophen-induced hepatotoxicity in mice. Toxicol Sci 2007; 99: 628-636.

6. Nakamura S, Kugiyama K, Sugiyama S, Miyamoto S, Koide S, Fukushima H et al. Polymorphism in the 5'-flanking region of human glutamate-cysteine ligase modifier subunit gene is associated with myocardial infarction. Circulation 2002; 105: 2968-2973.

7. Tosic M, Ott J, Barral S, Bovet P, Deppen P, Gheorghita F et al Schizophrenia and oxidative stress: glutamate cysteine ligase modifier as a susceptibility gene. Am J Hum Genet 2006; 79: 586-592.

8. Hanzawa R, Ohnuma T, Nagai $Y$, Shibata N, Maeshima $\mathrm{H}$, Baba $\mathrm{H}$ et al. No association between glutathione-synthesis-related genes and Japanese schizophrenia. Psychiatry Clin Neurosci 2011; 65: 39-46.

9. Bratosin D, Estaquier J, Petit F, Arnoult D, Quatannens B, Tissier JP et al. Programmed cell death in mature erythrocytes: a model for investigating death effector pathways operating in the absence of mitochondria. Cell Death Differ 2001; 8: 1143-1156.

10. Sarang Z, Madi A, Koy C, Varga S, Glocker MO, Ucker DS et al. Tissue transglutaminase (TG2) facilitates phosphatidylserine exposure and calpain activity in calcium-induced death of erythrocytes. Cell Death Differ 2007; 14: 1842-1844.

11. Lang KS, Duranton C, Poehlmann H, Myssina S, Bauer C, Lang F et al. Cation channels trigger apoptotic death of erythrocytes. Cell Death Differ 2003; 10: 249-256.

12. Foller M, Huber SM, Lang F. Erythrocyte programmed cell death. IUBMB Life 2008; 60: 661-668.

13. Lim SK, Kim H, Lim SK, bin AA, Lim YK, Wang Y et al. Increased susceptibility in Hp knockout mice during acute hemolysis. Blood 1998; 92: 1870-1877.

14. Hodges VM, Winter PC, Lappin TR. Erythroblasts from friend virus infected- and phenylhydrazine-treated mice accurately model erythroid differentiation. $\mathrm{Br} J$ Haematol 1999; 106: 325-334.

15. Hirschler-Laszkiewicz I, Zhang W, Keefer K, Conrad K, Tong Q, Chen SJ et al. Trpc2 depletion protects red blood cells from oxidative stress-induced hemolysis. Exp Hematol 2012; 40: 71-83.

16. Safeukui I, Buffet PA, Deplaine G, Perrot S, Brousse V, Ndour A et al. Quantitative assessment of sensing and sequestration of spherocytic erythrocytes by the human spleen. Blood 2012; 120: 424-430. 
17. Bunn HF, Esham WT, Bull RW. The renal handling of hemoglobin. I. Glomerular filtration J Exp Med 1969; 129: 909-923.

18. Zager RA. Rhabdomyolysis and myohemoglobinuric acute renal failure. Kidney Int 1996 49: 314-326.

19. Wu G, Fang YZ, Yang S, Lupton JR, Turner ND. Glutathione metabolism and its implications for health. J Nutr 2004; 134: 489-492.

20. Duranton C, Huber SM, Lang F. Oxidation induces a $\mathrm{Cl}(-)$-dependent cation conductance in human red blood cells. J Physiol 2002; 539: 847-855.

21. Lang PA, Kaiser S, Myssina S, Wieder T, Lang F, Huber SM. Role of Ca2 + -activated K + channels in human erythrocyte apoptosis. Am J Physiol Cell Physiol 2003; 285 C1553-C1560.

22. Fadok VA, Bratton DL, Rose DM, Pearson A, Ezekewitz RA, Henson PM. A receptor for phosphatidylserine-specific clearance of apoptotic cells. Nature 2000; 405: 85-90.

23. Boas FE, Forman L, Beutler E. Phosphatidylserine exposure and red cell viability in red cell aging and in hemolytic anemia. Proc Natl Acad Sci USA 1998; 95: 3077-3081.
24. Siems WG, Sommerburg O, Grune T. Erythrocyte free radical and energy metabolism. Clin Nephrol 2000; 53: S9-17.

25. Ginsburg H, Atamna $\mathrm{H}$. The redox status of malaria-infected erythrocytes: an overview with an emphasis on unresolved problems. Parasite 1994; 1: 5-13.

26. Agar NS, Sadrzadeh SM, Hallaway PE, Eaton JW. Erythrocyte catalase. A somatic oxidan defense? J Clin Invest 1986; 77: 319-321.

27. Beutler E, Dunning D, Dabe IB, Forman L. Erythrocyte glutathione S-transferase deficiency and hemolytic anemia. Blood 1988; 72: 73-77.

28. Nkhoma ET, Poole C, Vannappagari V, Hall SA, Beutler E. The global prevalence of glucose-6-phosphate dehydrogenase deficiency: a systematic review and meta-analysis. Blood Cells Mol Dis 2009; 42: 267-278.

29. Lang KS, Roll B, Myssina S, Schittenhelm M, Scheel-Walter HG, Kanz L et al. Enhanced erythrocyte apoptosis in sickle cell anemia, thalassemia and glucose-6-phosphate dehydrogenase deficiency. Cell Physiol Biochem 2002; 12 365-372. 